\title{
Greenhouse Evaluation of Binucleate Rhizoctonia for Control of $R$. solani in Soybean
}

\author{
F. U. Khan and B. D. Nelson, Department Plant Pathology, and T. C. Helms, Department of Plant Sciences, North \\ Dakota State University, Fargo 58105
}

\begin{abstract}
Khan, F. U., Nelson, B. D., and Helms, T. C. 2005. Greenhouse evaluation of binucleate Rhizoctonia for control of $R$. solani in soybean. Plant Dis. 89:373-379.

Nine isolates of binucleate Rhizoctonia (BNR) from soybean were screened in the greenhouse for control of Rhizoctonia solani anastomosis groups AG-4 and AG-2-2. Eight of nine BNR isolates, when combined with AG-4 or AG-2-2, significantly increased emergence and survival of soybean (cv. Ozzie) and reduced disease severity compared with AG-4 or AG-2-2 alone. The interaction of soybean cultivar and BNR isolates in the presence of AG-4 and AG-2-2 was also studied using three isolates of BNR, BNR-4, BNR-8-2, and BNR-8-3, and seven soybean cultivars. There was no BNR $\times$ cultivar interaction. With AG-4, BNRs significantly increased emergence and survival of cultivars and reduced disease severity, whereas with AG-2-2, BNRs reduced disease severity. Control of $R$. solani by BNRs was achieved in both a potting soil mix and natural soil. In the initial screening experiments, two BNR isolates reduced emergence, but in all subsequent experiments using three BNR isolates alone, there were no negative effects on germination, survival, or height of soybean plants, and there was no evidence of pathogenicity. In several experiments, BNRs alone significantly increased height of plants compared with the noninoculated controls. BNRs were consistently isolated from hypocotyls and roots, indicating colonization of tissues was associated with control. These BNR isolates may have potential use in management of $R$. solani in soybean, but will require rigorous testing under field conditions and more extensive studies of their biology.
\end{abstract}

Additional keywords: Ceratobasidium, Glycine max, Rhizoctonia root rot

Rhizoctonia solani (teleomorph: Thanatephorus cucumeris) is an important soilborne pathogen of soybean (Glycine max) in the United States and other countries $(9,36)$. The pathogen causes damping-off, root rot, stem rot, and foliar blight, and can cause substantial yield losses $(9,30,31)$. $R$. solani is also an important part of root rot/seedling disease complexes reported in many soybean producing areas $(34,35)$. Anastomosis groups (AG) AG-1 1A, 1 1B, $11 \mathrm{C}, 2,2-2,3,4$, and 5 are reported pathogenic on soybean $(23,28,36)$. AG-1 $1 \mathrm{~A}$ and AG-1 1B cause aerial blight and web blight, respectively, whereas the others cause seed, root, and stem rots. AG-4 and AG-2-2 are the most important in the north-central United States $(8,18,22,23)$.

In northern Minnesota and North Dakota, especially in the Red River Valley, soybean acreage has expanded greatly in recent years to about 1.6 million hectares. $R$. solani is common in soils in this region and is pathogenic on multiple row crops commonly grown $(23,33)$. Problems with

Corresponding author: B. D. Nelson

E-mail: Berlin.Nelson@ndsu.edu

Accepted for publication 8 November 2004.

DOI: 10.1094/PD-89-0373

(C) 2005 The American Phytopathological Society
$R$. solani in soybean are often associated with short soybean rotations, cropping histories that include other susceptible hosts such as dry beans (Phaseolus vulgaris) and sugar beets (Beta vulgaris), or poor environmental conditions for seed germination and seedling emergence (23). AG-4 is the predominant type damaging soybean in this area, but AG-2-2 also occurs in some fields (23). AG-5 is also common on soybean, but it is less virulent than the other two types (23).

While investigating the AG types of $R$. solani on soybean in this region, Nelson et al. (23) detected isolates of binucleate Rhizoctonia (BNR) on soybean roots. BNRs are also found on the roots of sugar beets (33), which are commonly grown in rotations with soybean. BNRs are morphologically similar to $R$. solani; however, they have binucleate cells, and the perfect state are species of Ceratobasidium (28). BNRs, like $R$. solani, are grouped on the basis of hyphal anastomosis $(4,25)$. They have shown potential as biocontrol agents on a variety of crops including dry bean, sugar beet, potato (Solanum tuberosum), tomato (Lycopersicon esculentum), turfgrass (Agrostis stolonifera), and poinsettias (Euphorbia pulcherrima) (3,6,11,1316,21). A single isolate of BNR has been shown to control the same pathogen on several unrelated hosts (13). BNRs are also known to be pathogens of various crops
(28). The objectives of this research were to (i) identify BNRs with the ability to control $R$. solani in soybean under controlled conditions, and (ii) test those BNRs on soybean cultivars with different genetic backgrounds.

\section{MATERIALS AND METHODS}

Cultures of BNR and $R$. solani. Two isolates of $R$. solani from soybean roots, AG-4 (85-1) and AG-2-2 (20-1), were used as pathogens throughout this study. These isolates were previously shown to be pathogenic on soybean (23). Nine BNR isolates were evaluated: BNR 2-2, 2-3, 4, 12-T-28, 26-A-4, 8-1, 8-2, 8-3, and 10. These BNR isolates were originally isolated from soybean roots $(17,23)$ and were all identified as AG-K by Khan (17). Identification was corroborated by Cubeta el al. (7) through molecular analysis. All isolates of BNR and $R$. solani were grown on potato dextrose agar (PDA) (Difco Laboratories, Detroit, MI) or twice-autoclaved barley grains in the dark for 7 and 14 days, respectively, and then stored at $-80^{\circ} \mathrm{C}$ in an ultrafreezer (24). To initiate growth from stored cultures, the frozen barley grains were placed directly on PDA, while the cultures on PDA were thawed for several minutes at $35^{\circ} \mathrm{C}$ and pieces of cultures were placed on PDA. Cultures were incubated in the dark at $22 \pm 0.5^{\circ} \mathrm{C}$. All inoculum was initiated directly from isolates stored in cryogenic storage for less than 12 months.

Determining control of $R$. solani by BNR. Initial screening of all nine BNR isolates for control of isolates of $R$. solani AG-4 and AG-2-2 was conducted in the greenhouse between May and June. All isolates were grown on $30 \mathrm{ml}$ of PDA in 9 $\times 2 \mathrm{~cm}$ petri dishes and incubated at $22 \pm$ $0.5^{\circ} \mathrm{C}$ in the dark for 9 days. Plastic cups $(150 \times 100 \mathrm{~mm})$ were filled with $400 \mathrm{ml}$ of pasteurized soil mix (equal parts of Glyndon sandy loam, peat moss, and vermiculite), and $10 \mathrm{ml}$ of Peters fertilizer solution (20-20-20; N-P-K) (W. R. Grace Co., Fogelsville, PA) was mixed into the soil mix. Treatments consisted of $R$. solani, BNR, or PDA alone, followed by $R$. solani + BNR treatment. The treatments were designed so that each cup had the same number of PDA slabs in the soil mix.

For those treatments where there was only one fungus or the control, in each cup filled with soil one culture of PDA+ mycelium or one PDA slab was placed 
face up on the soil. This was covered with $150 \mathrm{ml}$ of soil mix, and another PDA slab was placed face up on the soil. Ten seeds of the soybean cv. Ozzie were placed directly on the final PDA slab and covered with $150 \mathrm{ml}$ of soil mix to a depth of approximately $2 \mathrm{~cm}$. For the $R$. solani $+\mathrm{BNR}$ treatments, the placement of the PDA and addition of soil was similar except that the first layer inserted was the PDA+mycelium of $R$. solani, and the second layer was the PDA+mycelium of BNR that the seeds were placed on.

The experimental design was a split plot with isolates of $R$. solani as main plots and BNR as subplots with six replications (one cup per replication). Plants were illuminated with high-pressure sodium lamps $\left(1,000 \mu \mathrm{E} \cdot \mathrm{m}^{-2} \cdot \mathrm{s}^{-1}\right)$ for $16 \mathrm{~h}$ daily in addition to natural light. Greenhouse temperatures ranged from 20 to $30^{\circ} \mathrm{C}$. Plants were watered daily with tap water to maintain the soil near field capacity.

Emergence and survival were recorded 10 and 21 days after planting, respectively. Plants were then extracted from the soil and washed thoroughly in tap water, and disease severity was visually determined on hypocotyls of all plants per cup. Disease severity was based on a 1 to 5 scale, where $1=$ no symptoms, $2=$ lesions on hypocotyls $<3 \mathrm{~mm}$ or less than $25 \%$ girdling, $3=$ lesions 3 to $6 \mathrm{~mm}$ or 25 to $50 \%$ girdling, $4=$ lesions $>6 \mathrm{~mm}$ or $>50 \%$ girdling, and $5=$ plants $75 \%$ wilted or dead. A mean disease severity was calculated for each experimental unit (one cup) by dividing the sum of individual scores by the total number of plants scored. The experiment was repeated once.

Interaction of BNR with soybean cultivars. The effect of BNR isolates BNR-4, BNR-8-2, and BNR-8-3 on emergence, survival, and disease severity of soybean in the presence of $R$. solani was studied in the greenhouse. Seven cultivars, Glenwood, Maple Donovan, Maple Arrow, Simpson, Proto, Dawson, and Kato, each representing different genetic backgrounds within maturity group $\mathrm{O}$, were used in these studies. All the seed originated from the same location and year. The methods of plant growth, inoculum preparation, inoculation, and the greenhouse conditions were as previously described with one exception. The PDA cultures of BNR were placed directly on top (face up) of the $R$. solani AG-4 inoculum with no soil in between. This was done to place the AG-4 inoculum closer to the soybean seed, which would be more representative of field conditions. The experimental design was a split plot with cultivars assigned to main plots and treatments assigned to subplots with six replications (one cup per replication). Experiments with $R$. solani AG-4 and AG-2-2 were performed separately during May to July and August to October, respectively. In the experiment with AG-2-2, treatments were $R$. solani alone, $R$. solani $+\mathrm{BNR}$,
BNR alone, and a control with only PDA. The treatments with BNR alone were included specifically to test for evidence of pathogenicity of BNR on soybean. In the experiment with AG-4, treatments were similar, except those with BNR alone were not included.

Emergence, survival, and disease severity were recorded as previously described with the exception that survival and disease severity were recorded 28 days after planting. In the experiment with AG-2-2, the height (in centimeters, from soil to growing point) of all plants in cups was also recorded along with survival for treatments with BNR alone and the control with the PDA alone. Plant height was used to test the effects of BNR directly on plant growth. All experiments were repeated once.

Control in natural soil. The control of R. solani AG-4 and AG-2-2 by BNR-8-2 and BNR-8-3 was tested in natural soil (a nonpasteurized, Bearden fine-silty loam, $\mathrm{pH}$ 7.0) in the greenhouse during July to September with Ozzie soybean. The soil was collected from an apple orchard that had no previous history of other crops. These BNR were chosen based on their control activity in the first two experiments. The methods of plant growth, inoculum preparation, inoculation, and greenhouse conditions were as previously described for the interaction with cultivars. Experiments with isolates of AG-4 and AG-2-2 were conducted separately using a randomized complete block design with six replications (one cup per replication). Treatments were $R$. solani alone, BNR + $R$. solani, and a control of PDA alone. Emergence then survival, height $(\mathrm{cm})$, and disease severity for each treatment were recorded as previously described for the interaction with cultivars. All experiments were repeated once.

Reisolations from inoculated plants. After the termination of all greenhouse experiments, isolations were made from inoculated plants to determine the presence of $R$. solani and BNR. Isolations were also made from plants in treatments not inoculated with BNR or $R$. solani. Samples of roots or hypocotyls (5 to 20 samples per treatment) were washed in running tap water, then plated out on antibiotic water agar (15 g of agar per liter of $\mathrm{H}_{2} \mathrm{O}$; streptomycin sulfate, $0.15 \mathrm{mg} / \mathrm{ml}$ ) and incubated in the dark at $22 \pm 0.5^{\circ} \mathrm{C}$ in $9-\mathrm{cm}$ diameter petri dishes for 2 to 5 days. Mycelia characteristic of Rhizoctonia were subcultured onto and maintained on PDA. Cultures were then grown on $1.5 \%$ water agar for 2 to 3 days in the dark at $22 \pm$ $0.5^{\circ} \mathrm{C}$, stained with safranin $\mathrm{O}(2)$, and identified as either BNR or R. solani by examining morphology of the mycelium and the nuclear condition. The staining procedure consisted of flooding 2- to 4day-old mycelium on $2 \times 2 \mathrm{~cm}$ water agar blocks with equal parts of $0.5 \%$ safranin $\mathrm{O}$ and $3 \% \mathrm{KOH}$. Hyphae were examined at $\times 400$ to $\times 1,000$. Binucleate Rhizoctonia were identified by the characteristic right angled branching, constrictions of the branches at the point of origin, presence and location of dolipore septa, and the predominantly binucleate cells (28). The binucleate condition was verified by staining mycelium with DAPI (4',6'-diamidino2-phenylindole, hydrochloride) (19) using a Leitz Wetzlar epifluorescence microscope (E. Leitz, Wetzlar, Germany) with a BP340-380 excitation filter, a RKP400 dichroic filter, and a LP430 barrier filter.

In the experiments with the seven soybean cultivars, recovered isolates of BNR and $R$. solani were also identified by pairing with the original isolates used for inoculations and then observing anastomosis. Isolates were grown on PDA for 3 days, and mycelial disks were paired on water agar in 9-cm-diameter petri dishes at $22 \pm 0.5^{\circ} \mathrm{C}$ until hyphae overlapped 3 to 5 $\mathrm{mm}$. Hyphae were then stained with safranin $\mathrm{O}$ and examined at $\times 400$ for anastomosis. A positive anastomosis was a perfect fusion as described by Anderson (1) and Sneh et al. (28). An isolate was considered identified to AG if there were five positive anastomoses with the original isolate in each of two pairings.

Statistical analysis. All data were subjected to analysis of variance, then variances between similar experiments were tested for homogeneity, and data were pooled for combined analysis when appropriate. Analysis of variance was performed with the Statistical Analysis System (SAS Institute, Cary, NC). Fisher's protected least significant difference (LSD, $P=0.05$ ) was used as a posteriori multiple comparison test when analyzing data from experiments on initial screening of BNR for control activity. In all other experiments, treatments were compared and all relevant interactions were tested using linear contrasts. All contrasts were computed with the Statistical Analysis Package (12). In some experiments, two sets of orthogonal contrasts were analyzed to obtain all the necessary treatment comparisons. In the combined analyses, all experiment $\times$ contrast mean squares were tested for homogeneity using Bartlett's procedure (29). If variances were not homogeneous, each contrast was tested with the respective experiment $\times$ contrast mean square as the denominator of the $F$ test. Data from the emergence and survival counts were transformed with a $\log 10$ transformation, and the results of the statistical analysis on the transformed data were compared with the results using nontransformed data. Since there were no differences in the interpretation of the results with these analyses, the results are presented with the analysis of nontransformed data.

\section{RESULTS}

Determining control of $R$. solani by BNR. In the absence of BNR, $R$. solani 
AG-4 significantly $(P \leq 0.05)$ reduced emergence and survival of Ozzie soybean and caused lesions on hypocotyls of surviving plants (Tables 1 and 2). Conversely, AG-2-2 did not significantly reduce emergence, but was more virulent on older plants, reducing plant survival to a greater extent than AG-4 (Table 2). Overall, AG-22 caused significantly greater disease severity than AG-4 (Table 2).

All BNRs significantly increased emergence $(P \leq 0.05)$ and survival $(P \leq 0.01)$ of Ozzie soybean compared with treatments with AG-4 alone (Tables 1 and 2). Similarly, emergence was increased by all BNRs except BNR-10, and all BNRs increased survival compared with treatments with AG-2-2 alone. Overall, BNRs were more effective in increasing plant survival in the presence of AG-2-2 than they were in the presence of AG-4. BNRs differed significantly $(P \leq 0.05)$ from one another in increasing survival in the presence of either AG-2-2 or AG-4. BNR-8-2, BNR12T28, BNR-8-3, and BNR-4 resulted in the highest survival with AG-2-2, while the greatest increase in emergence in the presence of AG-4 was achieved with BNR-4, BNR-8-1, and BNR-8-3.

In the absence of $R$. solani, BNR-26A-4 and BNR-2-3 caused slight, but significant $(P \leq 0.05)$, decreases in emergence compared with the treatment with no fungi (PDA) (Table 2). Disease severity caused by AG-4 and AG-2-2 was significantly ( $P$ $\leq 0.05$ ) reduced by all BNR (Tables 1 and $2)$. BNRs differed in their ability to reduce disease severity caused by AG-2-2, but not by AG-4. The disease severity rating of plants infected by AG-2-2 ranged from 2.3

Table 1. Analysis of variance of effects of binucleate Rhizoctonia (BNR) on soybean in soil mix infested with $R$. solani AG-4 or AG-2-2a

\begin{tabular}{lrccc}
\hline & \multicolumn{4}{c}{ Mean squares $^{\mathbf{b}}$} \\
\cline { 2 - 5 } Source of variation & $\mathbf{d f}$ & Emergence $^{\mathbf{c}}$ & Survival & Disease severity $^{\mathbf{d}}$ \\
\hline Experiment (E) & 1 & $85.07^{* *}$ & $106.71^{* *}$ & 0.68 \\
Rep (experiment) & 10 & 0.96 & 0.22 & 0.19 \\
R. solani isolate (I) & 2 & 9.79 & 123.24 & $143.26^{* *}$ \\
BNR treatment (T) & 9 & $5.37^{*}$ & $19.92^{* *}$ & $1.83^{*}$ \\
I $\times$ T & 18 & $3.02^{*}$ & $7.16^{* *}$ & $1.25^{* *}$ \\
E $\times$ I & 2 & $9.04^{*}$ & $12.09^{* *}$ & 0.35 \\
E $\times$ T & 9 & 1.43 & 3.00 & 0.39 \\
E $\times$ I $\times$ T & 18 & 1.34 & 1.89 & 0.31 \\
Error (a) & 20 & & & \\
Error (b) & 270 & & & \\
Corrected total & 359 & & & \\
\hline
\end{tabular}

a Data from two experiments combined for analysis. Anastomosis groups AG-4 and AG-2-2 and nine isolates of BNR tested in the greenhouse on soybean cv. Ozzie.

b Values followed by * or ** are significant at $P=0.05$ or $P=0.01$, respectively.

${ }^{\mathrm{c}}$ Emergence and survival determined 10 days, and disease severity 21 days, after planting, respectively.

${ }^{\mathrm{d}}$ Disease severity based on a 1 to 5 scale where $1=$ no symptoms, $2=$ lesions on hypocotyls $<3 \mathrm{~mm}$ or less than $25 \%$ girdling, $3=$ lesions 3 to $6 \mathrm{~mm}$ or 25 to $50 \%$ girdling, $4=$ lesions $>6 \mathrm{~mm}$ or $>50 \%$ girdling, and $5=$ plants $75 \%$ wilted or dead. Disease severity was calculated by dividing sum of individual scores by number of plants scored. with BNR-8-3 to 3.2 with BNR-2-2 compared with 4.4 in the control.

Interactions of BNR and AG-2-2 with cultivars. Averaged across experiments and over cultivars, AG-2-2 did not significantly $(P>0.05)$ decrease emergence or survival, but did significantly $(P \leq 0.001)$ increase disease severity (Tables 3 and 4 ). There were significant $(P \leq 0.01)$ experiment $\times$ emergence and experiment $\times$ survival interactions with AG-2-2 causing 56 and $66 \%$ decreases in emergence and survival, respectively, in experiment 1 , while in experiment 2 , the decreases were 21 and $23 \%$, respectively. There were no interactions of cultivar for any factor, but there was a significant $(P \leq 0.01)$ experiment $\times$ cultivar $\times$ treatment interaction for emergence and survival (Table 3 ).

Averaged across experiments and cultivars, BNRs did not increase emergence or survival compared with treatments with AG-2-2 alone (Table 4). There were, however, significant $(P \leq 0.001)$ interactions of experiment $\times$ BNR effect on emergence and survival. Disease severity was significantly $(P \leq 0.001)$ reduced by all BNRs compared with AG-2-2 alone (Table 3), and there was a significant $(P \leq 0.001)$ interaction of experiment $\times$ BNR effect on disease severity (Table 3 ). There were no interactions between cultivar and BNR, but there were significant $(P \leq 0.05)$ interactions of experiment $\times$ cultivar $\times$ BNR for emergence, survival, and disease severity (Table 3).

Averaged across experiments and cultivars, BNRs alone did not significantly $(P>$ 0.05 ) affect emergence, survival, or disease severity compared with treatments with no fungi (Table 4). No lesions on hypocotyls or roots were observed on plants in the presence of only BNR. Plant height was significantly $(P \leq 0.05)$ increased by BNR compared with the control, and there were

Table 2. Effect of binucleate Rhizoctonia (BNR) on soybean plants in soil mix infested with R. solani AG-4 or AG-2-2a

\begin{tabular}{|c|c|c|c|c|c|c|c|c|c|}
\hline \multirow[b]{2}{*}{ Treatment } & \multicolumn{3}{|c|}{ Emergence $^{\mathrm{b}}$} & \multicolumn{3}{|c|}{ Survival $^{\mathrm{c}}$} & \multicolumn{3}{|c|}{ Disease severity $^{d}$} \\
\hline & AG-4 & AG-2-2 & Control $^{\mathrm{e}}$ & AG-4 & AG-2-2 & Control & AG-4 & AG-2-2 & Control \\
\hline BNR-2-2 & 9.0 & 8.7 & 9.2 & 8.9 & 7.4 & 9.2 & 1.0 & 3.2 & 1.0 \\
\hline BNR-2-3 & 9.0 & 8.7 & 8.7 & 9.0 & 7.5 & 8.5 & 1.1 & 3.0 & 1.0 \\
\hline BNR-4 & 9.4 & 9.0 & 9.0 & 9.3 & 7.8 & 8.9 & 1.0 & 2.6 & 1.0 \\
\hline BNR-26A-4 & 8.4 & 8.2 & 8.5 & 8.4 & 6.8 & 8.5 & 1.1 & 2.8 & 1.0 \\
\hline BNR-12T28 & 9.1 & 8.7 & 9.0 & 9.0 & 8.0 & 8.9 & 1.0 & 2.7 & 1.0 \\
\hline BNR-8-1 & 9.4 & 8.3 & 9.5 & 9.3 & 7.3 & 9.4 & 1.0 & 2.8 & 1.0 \\
\hline BNR-8-2 & 9.0 & 8.9 & 8.8 & 8.7 & 8.1 & 8.8 & 1.1 & 2.8 & 1.0 \\
\hline BNR-8-3 & 9.4 & 8.7 & 8.9 & 9.4 & 7.9 & 8.9 & 1.0 & 2.3 & 1.0 \\
\hline BNR-10 & 9.0 & 7.7 & 9.3 & 8.9 & 7.1 & 9.2 & 1.0 & 2.5 & 1.0 \\
\hline No BNR & 6.7 & 7.7 & 9.2 & 6.7 & 3.1 & 9.0 & 1.3 & 4.4 & 1.0 \\
\hline $\operatorname{LSD}(P=0.05)^{\mathrm{f}}$ & \multirow{2}{*}{\multicolumn{3}{|c|}{$\begin{array}{l}0.41 \\
1.76\end{array}$}} & \multicolumn{3}{|c|}{0.60} & \multicolumn{2}{|c|}{0.21} & \\
\hline $\operatorname{LSD}(P=0.05)^{\mathrm{g}}$ & & & & \multicolumn{2}{|c|}{2.13} & & \multicolumn{2}{|c|}{0.58} & \\
\hline
\end{tabular}

${ }^{\text {a }}$ Results of two experiments conducted in the greenhouse. Data pooled following testing for homogeneity of variance.

${ }^{\mathrm{b}}$ Mean number of plants per pot (10 seeds planted) 10 days after planting.

${ }^{c}$ Mean number of living plants per pot 21 days after planting.

d Disease severity based on a 1 to 5 scale where $1=$ no symptoms, 2 = lesions on hypocotyls $<3 \mathrm{~mm}$ or less than $25 \%$ girdling, $3=$ lesions 3 to $6 \mathrm{~mm}$ or 25 to $50 \%$ girdling, $4=$ lesions $>6 \mathrm{~mm}$ or $>50 \%$ girdling, and $5=$ plants $75 \%$ wilted or dead. Disease severity was calculated by dividing sum of individual scores by number of plants scored.

${ }^{\mathrm{e}}$ Control = soil mix not infested with $R$. solani.

${ }^{\mathrm{f}}$ Least significant difference (Fisher's protected LSD) between BNR treatments within the same AG of $R$. solani.

g Least significant difference between AGs of $R$. solani within the same BNR treatment. 
significant differences among BNR (Tables 3 and 4).

The analysis of variance (Table 3 ) indicated significant $(P \leq 0.05)$ interactions of experiment $\times$ treatment for emergence, survival, and disease severity, and experiment $\times$ cultivar $\times$ treatment for emergence and survival. There was also a significant $(P \leq 0.05)$ experiment $\times$ cultivar interaction.

Interaction of BNR and AG-4 with cultivars. Averaged across experiments and cultivars, AG-4 significantly $(P \leq 0.05)$ decreased emergence and survival, and increased disease severity (Tables 5 and 6 ). There were no significant $(P>0.05)$ interactions of cultivar $\times$ emergence, survival, or disease severity, but there were significant interactions $(P \leq 0.05)$ of experiment and experiment $\times$ cultivar for each of these factors (Tables 5 and 6 ).

Averaged across experiments and cultivars, all BNRs significantly $(P \leq 0.05)$ increased emergence and survival, and decreased disease severity on hypocotyls (Tables 5 and 6). There were no significant interactions $(P>0.05)$ of BNR isolate with cultivar, but there were significant interactions $(P \leq 0.05)$ of BNR isolate $\times$ experiment and BNR isolate $x$ experiment $x$ cultivar for emergence, survival, and disease severity (Table 6). There was also a significant $(P \leq 0.05)$ experiment $\times$ treatment interaction. Over experiments, BNR 8-3 and BNR-8-2 were similar in their ability to increase emergence and survival, but were significantly $(P \leq 0.05)$ different from BNR-4.

Control in natural soil. In natural soil, AG-2-2 did not decrease emergence or survival, but did significantly $(P \leq 0.01)$ increase disease severity and reduce plant height (Tables 7 and 8). There were no significant differences in emergence, survival, or disease severity for AG-2-2 across experiments.

BNRs did not significantly increase emergence and survival compared with AG-2-2 alone, but they significantly $(P \leq$
0.01) reduced disease severity and increased plant height (Tables 7 and 8). BNR-8-2 and BNR-8-3 had similar effects on height and disease severity in the presence of AG-2-2. There were significant $(P$ $\leq 0.01)$ interactions between experiment and treatment for emergence and survival (Table 7 and 8), with AG-2-2 reducing emergence and survival in the first experiment compared with the BNRs, which had an opposite effect. However, in the second experiment, AG-2-2 did not reduce emergence or survival. Also, between experiments, there were significant differences $(P \leq 0.05)$ between isolates of BNR for disease severity.

In natural soil, AG-4 significantly decreased $(P \leq 0.001)$ emergence and height of surviving plants, and significantly increased $(P \leq 0.001)$ disease severity (Ta-

Table 4. Effects of binucleate Rhizoctonia (BNR) on soybean cultivars and disease caused by R. solani AG-2-2 (RS) ${ }^{\mathrm{a}}$

\begin{tabular}{|c|c|c|c|c|}
\hline \multirow[b]{2}{*}{ Treatments } & \multicolumn{4}{|c|}{ Means $^{\mathbf{b}}$} \\
\hline & Emergence & Survival & Height $(\mathrm{cm})$ & Disease severity $^{\mathrm{c}}$ \\
\hline A. BNR-4+RS & 8.6 & 8.3 & $\ldots$ & 1.7 \\
\hline B. BNR-8-2+RS & 8.7 & 8.3 & $\ldots$ & 1.7 \\
\hline C. BNR-8-3+RS & 8.9 & 8.5 & $\ldots$ & 1.7 \\
\hline D. BNR-4 & 9.2 & 9.2 & 17.3 & 1.0 \\
\hline E. BNR-8-2 & 9.3 & 9.3 & 17.4 & 1.0 \\
\hline F. BNR-8-3 & 9.2 & 9.2 & 17.7 & 1.0 \\
\hline G. RS & 5.7 & 5.2 & & 3.5 \\
\hline H. No BNR or RS & 9.4 & 9.4 & 17.1 & 1.0 \\
\hline \multicolumn{5}{|l|}{ Contrasts $^{\mathrm{d}}$} \\
\hline 1. $A$ vs. $B+C$ & NS & NS & $\ldots$ & NS \\
\hline 2. B vs. C & NS & NS & $\ldots$ & NS \\
\hline 3. $\mathrm{D}$ vs. $\mathrm{E}+\mathrm{F}$ & NS & NS & * & NS \\
\hline 4. E vs. F & NS & NS & NS & NS \\
\hline 5. $\mathrm{G}$ vs. $\mathrm{A}+\mathrm{B}+\mathrm{C}$ & NS & NS & $\ldots$ & $* * *$ \\
\hline 6. $\mathrm{H}$ vs. $\mathrm{D}+\mathrm{E}+\mathrm{F}$ & NS & NS & $*$ & NS \\
\hline 7. G vs. H & NS & NS & $\ldots$ & $* * *$ \\
\hline \multicolumn{5}{|c|}{ Significant interactions } \\
\hline Experiment vs. 5 & $* * *$ & $* * *$ & $\ldots$ & $* *$ \\
\hline Experiment vs. 7 & $* * *$ & $* * *$ & $\ldots$ & ** \\
\hline $\mathrm{E} \times \mathrm{Cv}$ vs. 2 & NS & $*$ & $\ldots$ & NS \\
\hline $\mathrm{E} \times \mathrm{Cv}$ vs. 4 & $* *$ & $*$ & NS & NS \\
\hline $\mathrm{E} \times \mathrm{Cv}$ vs. 5 & $* * *$ & $*$ & $\ldots$ & $*$ \\
\hline $\mathrm{E} \times \mathrm{Cv}$ vs. 7 & $* *$ & NS & $\ldots$ & NS \\
\hline
\end{tabular}

${ }^{a}$ Results of two experiments. Data pooled following testing for homogeneity of variance. Experiments were split plots with cultivars as main plots and binucleate Rhizoctonia as subplots with six replications. Seven soybean cultivars were tested in the greenhouse in pasteurized soil mix.

${ }^{\mathrm{b}}$ Means are averaged over cultivars. Emergence (plants per cup) recorded 10 days, and height and survival recorded 28 days, after planting, respectively.

${ }^{\mathrm{c}}$ Disease severity at 28 days was evaluated on a 1 to 5 scale where $1=$ no symptoms, $2=$ lesions on hypocotyls $<3 \mathrm{~mm}$ or less than $25 \%$ girdling, $3=$ lesions 3 to $6 \mathrm{~mm}$ or 25 to $50 \%$ girdling, $4=$ lesions $>6 \mathrm{~mm}$ or $>50 \%$ girdling, and $5=$ plants $75 \%$ wilted or dead. Disease severity was calculated by dividing sum of individual scores by number of plants scored.

$\mathrm{d} *$, **, or $* * *=$ linear contrast significant at $P=0.05,0.01$, or 0.001 , respectively; NS $=$ not significant. Two sets of orthogonal contrasts were analyzed to obtain all necessary treatment comparisons. Contrast 7 is not orthogonal to contrasts 1 to 6.

Table 3. Analysis of variance of effects of binucleate Rhizoctonia (BNR) on soybean cultivars and disease caused by R. solani AG-2-2

\begin{tabular}{|c|c|c|c|c|c|c|}
\hline \multirow[b]{2}{*}{ Source of variation } & \multicolumn{6}{|c|}{ Mean squares $^{b}$} \\
\hline & df & Emergence $^{c}$ & Survival & Disease severity $^{d}$ & df & Height \\
\hline Experiment (E) & 1 & 9.76 & 3.01 & $14.52 * *$ & 1 & 172.23 \\
\hline Rep(experiment) & 10 & $2.12 *$ & 1.46 & $1.29 * * *$ & 10 & $202.60 * * *$ \\
\hline Cultivar $(\mathrm{Cv})$ & 6 & $21.53 *$ & 18.93 & $0.75^{*}$ & 6 & $164.64 * *$ \\
\hline Treatment (T) & 7 & 121.60 & 159.45 & $52.72 * * *$ & 3 & $5.43^{*}$ \\
\hline $\mathrm{Cv} \times \mathrm{T}$ & 42 & 3.68 & 3.93 & 0.19 & 18 & 0.78 \\
\hline $\mathrm{E} \times \mathrm{Cv}$ & 6 & $4.09 * *$ & $8.51 * * *$ & 0.16 & 6 & 10.49 \\
\hline $\mathrm{E} \times \mathrm{T}$ & 7 & $37.76 * * *$ & $49.12 * * *$ & $2.13 * * *$ & 3 & 0.44 \\
\hline $\mathrm{E} \times \mathrm{Cv} \times \mathrm{T}$ & 42 & $2.70 * * *$ & $2.40 * *$ & 0.09 & 18 & 1.26 \\
\hline Error (a) & 60 & & & & 60 & \\
\hline Error (b) & 490 & & & & 210 & \\
\hline Corrected total & 671 & & & & 335 & \\
\hline
\end{tabular}

${ }^{a}$ Data from two experiments combined for analysis. Three binucleate Rhizoctonia and seven cultivars tested in the greenhouse.

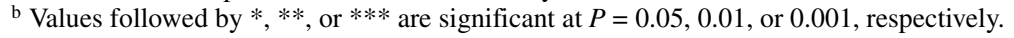

${ }^{\mathrm{c}}$ Emergence determined at 10 days, and survival, height $(\mathrm{cm})$, and severity at 28 days, after planting, respectively.

${ }^{\mathrm{d}}$ Disease severity was evaluated on a 1 to 5 scale where $1=$ no symptoms, $2=$ lesions on hypocotyls $<3 \mathrm{~mm}$ or less than $25 \%$ girdling, $3=$ lesions 3 to $6 \mathrm{~mm}$ or 25 to $50 \%$ girdling, $4=$ lesions $>6 \mathrm{~mm}$ or $>50 \%$ girdling, and $5=$ plants $75 \%$ wilted or dead. Disease severity was calculated by dividing sum of individual scores by number of plants scored. 
bles 7 and 8). The effect of AG-4 on emergence, survival, and disease severity was similar across experiments. BNR isolates significantly $(P \leq 0.001)$ increased emergence, survival, and height and reduced disease severity compared with AG-4 alone (Table 8). The increase in emergence and survival in the BNR treatments compared with AG-4 alone ranged between 73 and $90 \%$, and 78 and $98 \%$, respectively. The effects of BNRs on emergence and survival were similar across experiments; however, there was a significant $(P \leq 0.05)$ $\mathrm{BNR} \times$ experiment interaction for disease severity. In the first experiment, BNRs provided greater protection against AG-4 than occurred in experiment two. No infections of the controls (PDA only) were noted in any experiments in natural soil.

Reisolations from plants. In treatments with $R$. solani, or BNR alone, the presence of a multinucleate or binucleate Rhizoctonia was confirmed in all the respective samples collected in each experiment. Both fungi were readily isolated from plants grown in soil mix, but they were not recovered from all plants grown in natural soil. In treatments with $R$. solani + BNR, both fungi often grew out together onto the water agar and could be observed by staining nuclei, but no attempt was made to separate the isolates through subculturing. Following staining, the hyphae with binucleate cells were clearly distinguishable from the multinucleate hyphae of $R$. solani growing on the water agar. No Rhizoctonia was isolated from any samples from the noninoculated (PDA) controls. In the experiments with the seven cultivars, the presence of BNR-4, 8-2, 8-3, and AG-4 and AG-2-2 on roots and hypocotyls were confirmed through anastomosis with the original isolates.

\section{DISCUSSION}

This study identified BNR isolates that controlled $R$. solani AG-4 and AG-2-2 on different soybean cultivars under controlled conditions in soil mix and natural soil. This is the first study of this type on soybean and the first evidence that AG-K isolates can control $R$. solani. The three BNR selected for further study, BNR-4, BNR-8-2, and BNR-8-3, consistently reduced disease caused by both AGs of $R$. solani. The ability to control more than one pathogenic AG is important since there can be several AGs of $R$ solani in soybean depending on the soybean production area $(9,18,23)$. The data from this study do not clearly indicate if BNR will be more effective in controlling one AG of $R$. solani over another. In the experiments testing the nine BNR for control of $R$ solani, the BNR were generally more effective in increasing plant survival in the presence of AG-2-2 than of AG-4. However, those results were due to the fact that AG-2-2 killed more plants because of the higher temperatures in those greenhouse experiments. AG-2-2 is a more aggressive pathogen than AG-4 at higher temperatures (28). In other experiments with lower greenhouse temperatures, AG-2-2 did not reduce survival of plants. The initial screening of BNRs showed that isolate had an effect on efficacy of control, as reported by other researchers $(3,6,15)$. Some of the significant interactions with experiment in this study are most likely due to differences in greenhouse environmental conditions, primarily temperature, between experiments.

Table 5. Analysis of variance of effects of binucleate Rhizoctonia (BNR) on disease of soybean cultivars caused by $R$. solani $\mathrm{AG}-4^{\mathrm{a}}$

\begin{tabular}{lrccc}
\hline & \multicolumn{4}{c}{ Mean squares $^{\mathbf{b}}$} \\
\cline { 2 - 5 } Source of variation & df & Emergence $^{\mathbf{c}}$ & Survival & Disease severity $^{\mathbf{d}}$ \\
\hline Experiments (E) & 1 & $249.94^{* * *}$ & $245.34^{* * *}$ & $17.31^{*}$ \\
Rep (experiment) & 10 & $8.86^{* * *}$ & $8.34^{* * *}$ & $1.80^{* * *}$ \\
Cultivars (Cv) & 6 & $25.84^{*}$ & $26.25^{*}$ & 0.75 \\
Treatments (T) & 4 & $278.09^{* *}$ & $286.78^{* *}$ & $54.79^{* *}$ \\
$\mathrm{Cv} \times \mathrm{T}$ & 24 & 4.10 & 4.16 & 0.50 \\
$\mathrm{E} \times \mathrm{Cv}$ & 6 & 3.79 & 4.11 & 0.47 \\
$\mathrm{E} \times \mathrm{T}$ & 4 & $10.10^{* * *}$ & $9.70^{* * *}$ & $2.50^{* * *}$ \\
$\mathrm{E} \times \mathrm{Cv} \times \mathrm{T}$ & 24 & 2.31 & $2.68^{*}$ & $0.33^{* *}$ \\
Error (a) & 60 & & & \\
Error (b) & 280 & & & \\
Corrected total & 419 & & & \\
\hline
\end{tabular}

${ }^{a}$ Data from two experiments combined for analysis. Three isolates of binucleate Rhizoctonia and seven soybean cultivars tested in the greenhouse.

${ }^{b}$ Values followed by $*, * *$, or $* * *$ are significant at $P=0.05,0.01$, or 0.001 , respectively.

${ }^{\mathrm{c}}$ Emergence determined at 10 days, and survival and disease severity at 28 days, after planting, respectively.

${ }^{\mathrm{d}}$ Disease severity was evaluated on a 1 to 5 scale where $1=$ no symptoms, $2=$ lesions on hypocotyls $<3 \mathrm{~mm}$ or less than $25 \%$ girdling, $3=$ lesions 3 to $6 \mathrm{~mm}$ or 25 to $50 \%$ girdling, $4=$ lesions $>6 \mathrm{~mm}$ or $>50 \%$ girdling, and $5=$ plants $75 \%$ wilted or dead. Disease severity was calculated by dividing sum of individual scores by number of plants scored.

Table 6. Effects of binucleate Rhizoctonia (BNR) on soybean cultivars and disease caused by $R$. solani AG-4 (RS) $)^{\mathrm{a}}$

\begin{tabular}{lccc}
\hline & \multicolumn{3}{c}{ Means $^{\mathbf{b}}$} \\
\cline { 2 - 4 } Treatments & Emergence & Survival & Disease severity $^{\mathbf{c}}$ \\
\hline A. BNR-4+RS & 7.6 & 7.6 & 1.5 \\
B. BNR-8-2+RS & 7.7 & 7.7 & 1.4 \\
C. BNR-8-3+RS & 7.8 & 7.8 & 1.4 \\
D. RS & 4.3 & 4.2 & 3.1 \\
E. No BNR or RS & 9.2 & 9.2 & 1.0 \\
Contrasts & & & $*$ \\
1. A+B+C vs. D & $*$ & $*$ & $\mathrm{NS}$ \\
2. A vs. B+C & $\mathrm{NS}$ & $\mathrm{NS}$ & $\mathrm{NS}$ \\
3. B vs. C & $\mathrm{NS}$ & $*$ & \\
4. D vs. E & $*$ & $* *$ & $* * *$ \\
Significant interactions & & $*$ & NS \\
Experiment (E) vs. 1 & $* *$ & $*$ & $* * *$ \\
Experiment vs. 2 & $*$ & $* * *$ & $* * *$ \\
Experiment vs. 4 & $*$ & $*$ & \\
E $\times$ Cv vs. 1 & $* *$ & $\mathrm{NS}$ & \\
E $\times$ Cv vs. 4 & & & \\
\hline
\end{tabular}

${ }^{a}$ Results of two experiments. Data pooled following testing for homogeneity of variance. The experiments were split plots with cultivars as main plots and binucleate Rhizoctonia as subplots with six replications. Seven soybean cultivars were tested in the greenhouse in pasteurized soil mix.

${ }^{b}$ Means are averaged across cultivars. Emergence (plants per cup) was recorded at 10 days, and survival and disease severity at 28 days, after planting, respectively.

${ }^{\mathrm{c}}$ Disease severity was evaluated on a 1 to 5 scale, where $1=$ no symptoms, $2=$ lesions on hypocotyls $<3 \mathrm{~mm}$ or less than $25 \%$ girdling, $3=$ lesions 3 to $6 \mathrm{~mm}$ or 25 to $50 \%$ girdling, $4=$ lesions $>6 \mathrm{~mm}$ or $>50 \%$ girdling, and $5=$ plants $75 \%$ wilted or dead. Disease severity was calculated by dividing sum of individual scores by number of plants scored.

$\mathrm{d} *, * *$, or $* * *=$ linear contrast significant at $P=0.05,0.01$, or 0.001 , respectively; NS $=$ not significant. Two sets of orthogonal contrasts were analyzed to obtain all necessary treatment comparisons. Contrast 4 is not orthogonal to contrasts 1 to 3 . 
from $R$. solani AG-2-2 or AG-4 by BNR may be unaffected by cultivar. This finding agrees with research by Escande and Echandi (11), who reported that the BNR isolate 234-CG provided equal protection to three potato cultivars in soil infested with AG-3 in North Carolina.

Some BNRs have been reported to be plant pathogens $(5,20,28)$. For example, Ploetz et al. (26) found that nine isolates of CAG-3 (AG-E) recovered from soybean seedlings and soil were all pathogenic on soybean. In the initial screening of BNRs for control of $R$. solani in this study, two isolates, BNR-2-3 and BNR-26A-4, reduced emergence of soybean, but in all experiments with BNR-4, BNR-8-2, and BNR-8-3, there was no negative effect on emergence, survival, disease severity, or height of plants. Thus, the three BNR selected for further testing do not appear to be pathogenic on soybean. The pathogenicity of BNR-2-3 and BNR-26A-4 will require further testing to ascertain their effects on soybean. Echandi (10) also reported that BNRs used for biological control of $R$. solani on potato were not pathogenic on soybean. The pathogenicity of the AG-K isolates from this study on crops other than soybean is unknown.

In this study, BNRs alone significantly increased plant height compared with the noninoculated control. The reason for this height response is unknown. Since plants were growing in pasteurized soil mix, it is unlikely the BNRs were controlling some unidentified soil microorganisms that otherwise would have interfered with plant growth. A more plausible reason could be related to the mechanism of biocontrol of $R$. solani by BNR AG-K, which is a novel form of induced resistance (27). It is possible that the physiological changes in soybean may have been induced by the BNR, which resulted in increased plant height. This possibility deserves additional study.

Whether BNRs have any practical use in on-farm management of $R$. solani on soybean will require extensive investigations on many aspects of the biology of BNRs. AG-4 and AG-2-2 differ in their ecology in the Red River Valley of North Dakota and
Minnesota. AG-4 is primarily a seedling/young plant pathogen, while AG-2-2 is generally found on older plants (23). BNR, therefore, would have to work in different soil and plant environments to be effective. The host range of the three BNR AG-K isolates will need to be determined and inoculum formulations developed.

Table 8. Effects of binucleate Rhizoctonia (BNR) on soybean plants in natural soil infested with $R$ solani $\mathrm{AG}-4$ or $\mathrm{AG}-2-2^{\mathrm{a}}$

\begin{tabular}{|c|c|c|c|c|}
\hline \multirow[b]{2}{*}{ Treatments } & \multicolumn{4}{|c|}{ Means $^{\mathbf{b}}$} \\
\hline & Emergence & Survival & Disease severity & Height $(\mathrm{cm})$ \\
\hline \multicolumn{5}{|l|}{ Experiments with AG-2-2 } \\
\hline A. AG-2-2+BNR-8-3 & 8.5 & 8.5 & 1.5 & 15.9 \\
\hline B. AG-2-2+BNR-8-2 & 7.9 & 7.9 & 1.7 & 15.6 \\
\hline C. AG-2-2 & 6.7 & 6.2 & 2.8 & 13.3 \\
\hline D. NO AG-2-2 or BNR & 8.5 & 8.5 & 1.0 & 16.6 \\
\hline \multicolumn{5}{|l|}{ Contrasts $^{\mathrm{c}}$} \\
\hline 1. C vs. D & NS & NS & $* *$ & ** \\
\hline 2. $A+B$ vs. $C$ & NS & NS & ** & ** \\
\hline 3. A vs. B & NS & NS & NS & NS \\
\hline \multicolumn{5}{|l|}{ Significant interactions } \\
\hline Experiment vs. 2 & $* *$ & * & NS & NS \\
\hline Experiment vs. 3 & NS & NS & $* *$ & NS \\
\hline \multicolumn{5}{|l|}{ Experiments with AG-4 } \\
\hline A. AG-4+BNR-8-2 & 7.5 & 7.4 & 1.5 & 18.7 \\
\hline B. AG-4+BNR-8-3 & 8.2 & 8.2 & 1.4 & 18.7 \\
\hline C. AG-4 & 4.3 & 4.2 & 3.6 & 12.6 \\
\hline D. No AG-4 or BNR & 9.5 & 9.5 & 1.0 & 18.3 \\
\hline \multicolumn{5}{|l|}{ Contrasts ${ }^{\mathrm{c}}$} \\
\hline 1. C vs. D & $* * *$ & $* * *$ & $* * *$ & $* * *$ \\
\hline 2. $\mathrm{A}+\mathrm{B}$ vs. $\mathrm{C}$ & $* * *$ & $* * *$ & $* * *$ & $* * *$ \\
\hline 3. A vs. B & $* *$ & $*$ & NS & NS \\
\hline \multicolumn{5}{|l|}{ Significant interactions } \\
\hline Experiment vs. 2 & NS & NS & $*$ & NS \\
\hline
\end{tabular}

${ }^{a}$ Experiments with AG-2-2 and AG-4 were conducted separately. Experiments were repeated and data pooled following testing for homogeneity of variance.

${ }^{\mathrm{b}}$ Emergence (plants per cup) was recorded 10 days, and height, survival, and disease severity 28 days, after planting, respectively. Disease severity evaluated on a 1 to 5 scale, where $1=$ no symptoms, $2=$ lesions on hypocotyls $<3 \mathrm{~mm}$ or less than $25 \%$ girdling, $3=$ lesions 3 to $6 \mathrm{~mm}$ or 25 to $50 \%$ girdling, $4=$ lesions $>6 \mathrm{~mm}$ or $>50 \%$ girdling, and $5=$ plants $75 \%$ wilted or dead. Disease severity was calculated by dividing sum of individual scores by number of plants scored.

c *,**, or $* * *=$ linear contrast significant at $P=0.05,0.01$, or 0.001 , respectively; NS $=$ not significant.

Table 7. Analysis of variance of effects of binucleate Rhizoctonia on soybean plants in natural soil infested with R. solani AG-4 or AG-2-2a

\begin{tabular}{|c|c|c|c|c|c|}
\hline \multirow[b]{2}{*}{ Sources of variation } & \multicolumn{5}{|c|}{ Mean squares $^{\mathbf{b}}$} \\
\hline & df & Emergence $^{c}$ & Survival & Disease severity $^{d}$ & Height \\
\hline \multicolumn{6}{|c|}{ In soil infested with AG-2-2 } \\
\hline Experiments (E) & 1 & 1.33 & 1.69 & 0.01 & $114.52 * *$ \\
\hline Rep (experiments) & 10 & 2.18 & 2.45 & 1.13 & 1.15 \\
\hline Treatments (T) & 3 & 8.16 & 14.63 & $6.17 *$ & $24.86^{*}$ \\
\hline $\mathrm{E} \times \mathrm{T}$ & 3 & $5.94 * *$ & $5.35^{*}$ & 0.29 & 1.02 \\
\hline Error & 30 & & & & \\
\hline Corrected total & 47 & & & & \\
\hline \multicolumn{6}{|c|}{ In soil infested with AG-4 } \\
\hline Experiments (E) & 1 & 2.52 & 2.08 & 0.001 & 1.20 \\
\hline Rep (experiments) & 10 & $3.52 *$ & $3.36^{*}$ & 0.04 & 1.40 \\
\hline Treatments $(\mathrm{T})$ & 3 & $58.19 * *$ & $62.27 * *$ & $15.91 * *$ & $165.84 * *$ \\
\hline $\mathrm{E} \times \mathrm{T}$ & 3 & 0.08 & 2.08 & 0.09 & 1.12 \\
\hline Error & 30 & & & & \\
\hline Corrected total & 47 & & & & \\
\hline
\end{tabular}


Finally, rigorous field testing under a variety of conditions will be required. The results of this research plus other research conducted in our laboratory (27) is strong evidence that control of $R$. solani by BNRs requires colonization of the soybean tissue prior to infection by the pathogen. For this reason, the seed was placed directly on the BNR mycelium so the roots would grow through the BNR prior to contacting the culture of $R$. solani. In our preliminary research, when we used other methods where the roots did not come in contact with the BNR prior to $R$ solani, disease control was lacking. Achieving this early colonization of soybean in normal soybean production practices may be more difficult but possible through seed treatment with BNR.

\section{LITERATURE CITED}

1. Anderson, N. A. 1982. The genetics and pathology of Rhizoctonia solani. Annu. Rev. Phytopathol. 20:329-347.

2. Bandoni, R. J. 1979. Safranin O as a rapid nuclear stain for fungi. Mycologia 71:873-874.

3. Burpee, L. L., and Goulty, L. G. 1984. Suppression of brown patch disease of creeping bent grass by isolates of nonpathogenic Rhizoctonia spp. Phytopathology 74:692-694.

4. Burpee, L. L., Sanders, P. L., Cole H., Jr., and Sherwood, R. T. 1980. Anastomosis groups among isolates of Ceratobasidium cornigerum (Bourd.) and related fungi. Mycologia 72:689701.

5. Burpee, L. L., Sanders, P. L., Cole H., Jr., and Sherwood, R. T. 1980. Pathogenicity of Ceratobasidium cornigerum and related fungi representing five anastomosis groups. Phytopathology 70:843-846.

6. Cardoso, J. E., and Echandi, E. 1987. Biological control of Rhizoctonia root rot of snap bean with binucleate Rhizoctonia-like fungi. Plant Dis. 71:167-170.

7. Cubeta, M. A., Echandi, E., Abernethy, T., and Vilgalys, R. 1991. Characterization of anastomosis groups of binucleate Rhizoctonia species using restriction analysis of an amplified ribosomal RNA gene. Phytopathology 81:13951400.

8. Dorrance, A. E., Kleinhenz, M. D., McClure, S. A., and Tuttle, N. T. 2003. Temperature, moisture, and seed treatment effects on Rhizoctonia solani root rot of soybean. Plant Dis. 87:533-538.
9. Doupnik, B., Jr. 1993. Soybean production and disease loss estimates for north central United States from 1989 to 1991. Plant Dis. 77:11701171.

10. Echandi, E. 1988. Selection of binucleate Rhizoctonia like fungi for control of Rhizoctonia root rot of snap bean. Page 37 in: Abstracts of Papers. Int. Congr. Plant Pathol., 5th. Edinburgh, Scotland.

11. Escande, A. R., and Echandi, E. 1991. Protection of potato from Rhizoctonia canker with binucleate Rhizoctonia fungi. Plant Pathol. 40:197-202.

12. Hammond, J. J. 1983. Statistical analysis packages for an Apple II plus. Page 20 in: Agronomy Abstracts. American Society of Agronomy, Madison, WI.

13. Harris, A. R., Schisler, D. A., and Ryder, M. H. 1993. Binucleate Rhizoctonia isolates control damping-off caused by Pythium ultimum var. sporangiiferum and promote growth in Capsicum and Celosia seedlings in pasteurized potting medium. Soil Biol. Biochem. 25:909-914.

14. Herr, L. J. 1986. Biocontrol of Rhizoctonia crown rot of sugar beets by binucleate Rhizoctonia spp. and Laetisaria arvalis. (Abstr.) Phytopathology 76:1103.

15. Herr, L. J. 1988. Biocontrol of Rhizoctonia crown rot of sugar beet by binucleate Rhizoctonia spp. and Laetisaria arvalis. Ann. Appl. Biol. 113:107-118.

16. Hwang, J., and Benson, D. M. 2002. Biocontrol of Rhizoctonia stem and root rot of poinsettia with Burkholderia cepacia and binucleate Rhizoctonia. Plant Dis. 86:47-53.

17. Khan, F. U. 1993. Biocontrol of Rhizoctonia solani on soybean with binucleate Rhizoctonia. Ph.D. thesis. North Dakota State University, Fargo.

18. Liu, Z., and Sinclair, J. B. 1991. Isolates of Rhizoctonia solani anastomosis group 2-2 pathogenic to soybean. Plant Dis. 75:682-687.

19. Martin, B. 1987. Rapid identification of Rhizoctonia spp. associated with diseased turf grass. Plant Dis. 71:47-49.

20. Martin, S. B. 1988. Identification, isolation, frequencies and pathogenicity of anastomosis groups of binucleate Rhizoctonia species from strawberry roots. Phytopathology 78:379-384.

21. Muslim, A., Horinouchi, H., and Hyakumachi, M. 2003. Control of Fusarium crown and root rot of tomato with hypovirulent binucleate Rhizoctonia in soil and rock wool systems. Plant Dis. 87:739-747.

22. Muyolo, N. G., Lipps, P. E., and Schmitthenner, A. F. 1993. Anastomosis grouping and variation in virulence among isolates of Rhizoctonia solani associated with dry bean and soybean in Ohio and Zaire. Phytopa- thology 83:438-444.

23. Nelson, B., Helms, T., Christianson, T., and Kural, I. 1996. Characterization and pathogenicity of Rhizoctonia from soybean. Plant Dis. 80:74-80.

24. Nelson, B. D., and Kural, I. 1990. Cryogenic preservation of Rhizoctonia cultures. (Abstr.) Phytopathology 80:1042.

25. Ogoshi, A., Oniki, M., Sakai, A., and Ui, T. 1979. Anastomosis grouping among isolates of binucleate Rhizoctonia. Trans. Mycol. Soc. Jpn. 20:33-39.

26. Ploetz, R. C., Mitchell, D. J., and Gallaher, R. N. 1985. Characterization and pathogenicity of Rhizoctonia species from a reduced-tillage experiment multicropped to rye and soybean in Florida. Phytopathology 75:833-839.

27. Poromarto, S. H., Nelson, B. D., and Freeman, T. P. 1998. Association of binucleate Rhizocto nia with soybean and mechanism of biocontrol of Rhizoctonia solani. Phytopathology 88:1056-1067.

28. Sneh, B., Burpee, L., and Ogoshi, A. 1991. Identification of Rhizoctonia species. American Phytopathological Society, St. Paul, MN.

29. Steel, R. G. D., and Torrie, J. H. 1980. Principles and Procedures of Statistics. McGrawHill, New York.

30. Tachibana, H. 1968. Rhizoctonia root rot epidemic of soybean in central Iowa, 1967. Plant Dis. Rep. 52:613-614.

31. Tachibana, H., Jowett, D., and Fehr, W. R. 1971. Determination of losses in soybean caused by Rhizoctonia solani. Phytopathology 61:1444-1446.

32. Vasantha Devi, T., Malar Vizhi, R., Sakthivel, N., and Gnanamanickam, S. S. 1989. Biological control of sheath blight of rice in India with antagonistic bacteria. Plant Soil 119:325-330.

33. Windels, C. E., and Nabben, D. J. 1989. Characterization and pathogenicity of anastomosis groups of Rhizoctonia solani isolated from Beta vulgaris. Phytopathology 79:88-93.

34. Wrather, J. A., Anderson, T. R., Arsyad, D. M., Tan, Y., Ploper, L. D., Porta-Puglia, A., Ram, H. H., and Yorinori, J. T. 2001. Soybean disease loss estimates for the top ten soybeanproducing countries in 1998. Can. J. Plant Pathol. 23:115-121.

35. Wrather, J. A., Koenning, S. R., and Anderson, T. R. 2003. Effect of diseases on soybean yields in the United States and Ontario (1999 to 2002). Online. Plant Health Progress doi:10.1094/PHP-2003-0325-01-RV.

36. Yang, X. B. 1999. Rhizoctonia damping-off and root rot. Pages 45-46 in: Compendium of Soybean Diseases, 4th ed. G. L. Hartman, J. B. Sinclair, and J. C. Rupe, eds. American Phytopathological Society, St. Paul, MN. 